OPEN ACCESS

Edited by:

Jinjin $\mathrm{Li}$,

Shanghai Jiao Tong University, China

Reviewed by:

Kaisheng Zhang,

Hefei Institutes of Physical Science

(CAS), China

Bai Sun,

Anhui Jianzhu University, China

*Correspondence:

Jinyun Liu

jyliu@ahnu.edu.cn

Chaoquan $\mathrm{Hu}$

cqhu@ipe.ac.cn

${ }^{\dagger}$ These authors have contributed equally to this work

Specialty section:

This article was submitted to Interdisciplinary Physics, a section of the journal

Frontiers in Physics

Received: 19 February 2021

Accepted: 08 March 2021

Published: 01 April 2021

Citation:

Han T, Qi M, Yang S, Diao X, Long J,

Zhu M, Xu X, Hu C and Liu J (2021)

Electron and lon Transport of Tin

Dioxide in Secondary Batteries:

Enhancement Approaches,

Mechanisms, and Performance.

Front. Phys. 9:669736.

doi: 10.3389/fphy.2021.669736

\section{Electron and Ion Transport of Tin Dioxide in Secondary Batteries: Enhancement Approaches, Mechanisms, and Performance}

\author{
Tianli Han ${ }^{1 \dagger}$, Mingqiang Qi ${ }^{1+}$, Shanshan Yang ${ }^{1 \dagger}$, Xinya Diao ${ }^{1}$, Jiawei Long ${ }^{1}$, Mengfei Zhu ${ }^{1}$, \\ Xiaoyong $\mathrm{Xu}^{2}$, Chaoquan $\mathrm{Hu}^{3,4 *}$ and Jinyun $\mathrm{Liu}^{1 *}$ \\ ${ }^{1}$ Anhui Provincial Engineering Laboratory for New-Energy Vehicle Battery Energy-Storage Materials, College of Chemistry \\ and Materials Science, Anhui Normal University, Wuhu, China, ${ }^{2}$ College of Chemistry and Material Engineering, Chaohu \\ University, Hefei, China, ${ }^{3}$ Nanjing IPE Institute of Green Manufacturing Industry, Nanjing, China, ${ }^{4}$ State Key Laboratory of \\ Multiphase Complex Systems, Institute of Process Engineering, Chinese Academy of Sciences, Beijing, China
}

Secondary batteries have been important across several aspects of daily life and industrial manufacture. The electron and ion transport of electrodes significantly affects the energy-storage performance of batteries. Among many fascinating materials, transition metal oxides have been considered promising as candidate electrode materials of high-performance batteries owing to their high theoretical capacity and good stability. Herein, tin dioxide is chosen as a representative transition metal oxide to show the specific electron and ion transport in some types of secondary batteries including lithium-ion, lithium-sulfur, potassium-ion batteries, etc. The way to optimize the structure and the strategies to enhance electron and ion transport have been summarized. Recently, tin dioxide doping and the preparation of tin dioxide-based composites have been reported. In addition, the main challenges and possible prospects are also proposed, which provide important suggestions for researchers to develop high-performance energy-storage materials and to explore new physical science.

Keywords: electron transfer, ion diffusion, transition metal oxide, composite, doping

\section{INTRODUCTION}

Depending on the rapid development of modern society, the production of clean, renewable energy has become an important direction [1-3] that is necessary to the development of energy storage systems. Secondary batteries have been considered the best choice. In the past few decades, apart from lithium-ion (Li-ion) batteries, some new types of batteries, such as lithium-sulfur (Li-S), sodium ( $\mathrm{Na}$ )-ion, and potassium (K)-ion batteries, have been developed [4-7]. The energy-storage performance relies on the property of the electrode materials, and this is especially relevant when it comes to large theoretical capacity and good stability.

As a transition metal oxide, tin oxide $\left(\mathrm{SnO}_{2}\right)$ has a high theoretical capacity, good safety, and a low cost of production, which has attracted much attention [8-11]. However, $\mathrm{SnO}_{2}$, as a semiconductor, has poor conductivity and ion diffusivity, which highly restricts its electrochemical performance $[12,13]$. After many cycles, the electrode structure changes greatly, which results in capacity decay $[14,15]$. It is important to improve the electron and ion transport of the $\mathrm{SnO}_{2}$ electrodes, which is mainly achieved by constructing composites and doping [16-18]. In this 
review, we focus on the main strategies to improve the electron transfer and ion diffusion of $\mathrm{SnO}_{2}$ in batteries, which will be important for the broad researchers who are working on energy storage and related physical sciences.

\section{CHALLENGES FOR ELECTRON AND ION TRANSPORT}

Even though $\mathrm{SnO}_{2}$ has been widely studied for secondary batteries, it has several disadvantages that restrict its electrochemical performance and practical applications, such as low electronic conductivity and the poor ability of ion transport. For example, the conductivity of $\mathrm{SnO}_{2}$ at room temperature reported by Park et al. was only $1.242 \times 10^{-8} \mathrm{~S} \mathrm{~cm}^{-1}$ [12]. In addition, Xie et al. reported that the Li-ion diffusion coefficient of amorphous $\mathrm{SnO}_{2}$ thin film was $10^{-15}-10^{-13} \mathrm{~cm}^{2} \mathrm{~s}^{-1}$ [13]. It greatly limits the overall capacity and rate-performance of $\mathrm{SnO}_{2}$-based secondary batteries. Moreover, the $\mathrm{SnO}_{2}$ exhibits a large volume change during the lithiation-delithiation, which makes the electrode gradually pulverize, resulting in a rapid capacity decay.

Recently, it was reported the physical properties of $\mathrm{SnO}_{2}$ can be adjusted by controlling the morphology [2]. Many researchers have selectively focused on the adjustment of the morphology of nanostructured $\mathrm{SnO}_{2}$ in secondary battery systems. It was reported the conductivity of a single $\mathrm{SnO}_{2}$ nanowire was $0.1-$ $0.9 \mathrm{~S} \mathrm{~cm}^{-1}$ [19]. Park et al. employed $\mathrm{SnO}_{2}$ nanowires as anode materials for Li-ion batteries and compared the electrochemical performance with $\mathrm{SnO}_{2}$ powders. $\mathrm{SnO}_{2}$ nanowires showed a high lithium-storage performance [20]. The improvement of the electrochemical performance of $\mathrm{SnO}_{2}$ nanowires was ascribed to the large surface area. Yin et al. indicated the electrochemical performance of $\mathrm{SnO}_{2}$ nanosheets for Li-ion batteries was improved because the nanostructure increased the surface area, enhanced the structural stability, and shortened the diffusion distance of ions and electrons [21].

Compared to some morphologies such as $1 \mathrm{D}$ nanowires [22, 23], nanorods [24, 25], nanotubes [26], and two-dimensional (2D) nanosheets [27, 28], three-dimensional (3D) porous structures provide sufficient voids to buffer volume expansion. Since then, it has attracted great attention [29]. In 2017, Li et al. prepared a dumbbell hollow porous $\mathrm{SnO}_{2}$ anode for a $\mathrm{Li}$-ion battery, and it exhibited a high capacity [10]. There were nanopores in the porous shell, which promoted electrolyte transport and Li-ion diffusion; and the hollow porous structure provided space for buffer volume expansion. Zhang et al. prepared uniform multi-shell $\mathrm{SnO}_{2}$ hollow microspheres through a continuous hard template method, which was used as the anode of the Li-ion battery [30]. Each shell of the multi-shell hollow structure could form parallel resistance to improve the conductivity.

Nanostructured $\mathrm{SnO}_{2}$ can not only improve the electronic conductivity but also shorten the Li-ion diffusion pathway by improving the electrode-electrolyte interface properties $[3,31]$. However, the electrochemical performance of the nanostructured $\mathrm{SnO}_{2}$ hinders the application in large-scale secondary batteries. In some studies, it was found that surface coating and elemental doping improved the performance $[3,9,32]$. Researchers have developed several strategies to improve the electron and ion transport of $\mathrm{SnO}_{2}$ to enhance the energy-storage performance, and these have potential for large-scale application.

\section{ELECTRON AND ION TRANSPORT OF $\mathrm{SnO}_{2}$ COMPOSITES \\ $\mathrm{SnO}_{2} @ \mathrm{C}$ Composites in Li-Ion Batteries}

Carbonaceous materials have good electrical conductivity, exhibiting a synergistic effect with $\mathrm{SnO}_{2}$ to improve the overall electronic conductivity [33]. Guo et al. prepared porous carboncoated $\mathrm{SnO}_{2}$ nanoparticles $\left(\mathrm{SnO}_{2} @ \mathrm{PC}\right)$ by using glucose as the carbon source [34]. Porous carbon provided a fast electron/ion transport pathway, which prevents the crushing and aggregation of $\mathrm{SnO}_{2}$ nanoparticles and promotes the formation of stable solid electrolyte interface (SEI) films. Moreover, the highly specific surface area provided more active centers for Li storage and promoted ion/electron transport. When the carbon content was $14.1 \%$, the discharge capacity was $1130.1 \mathrm{mAh} \mathrm{g}^{-1}$ after 100 cycles at $0.2 \mathrm{~A} \mathrm{~g}^{-1}$.

Since graphene was discovered by Andre and Konstantin Novoselov in 2004, it has attracted wide attention in many fields. Owing to its excellent mechanical properties and electrical conductivity, graphene has been used for energy storage [35]. Many studies have focused on combining graphene with a transition metal oxide like $\mathrm{SnO}_{2}$. Chen et al. reported a $\mathrm{SnO}_{2}$ /graphene composite, which was beneficial to improve the electrochemical performance [36]. The green approach to prepare the $\mathrm{SnO}_{2}$ /graphene composites directly anchored $\mathrm{SnO}_{2}$ nanoparticles on graphene nanosheets via $\mathrm{Sn}-\mathrm{O}-\mathrm{C}$ bonds. The prepared $\mathrm{SnO}_{2}$ /graphene composite exhibited a capacity of 1420 $\mathrm{mAh} \mathrm{g}^{-1}$ at $0.1 \mathrm{~A} \mathrm{~g}^{-1}$ after 90 cycles and good cycling retention of $97 \%$ at $1 \mathrm{~A} \mathrm{~g}^{-1}$ after 230 cycles.

Some investigations have indicated that the composites of $\mathrm{SnO}_{2}$ with carbon materials often suffered from material loss during long-term cycles, which leads to the increase of resistance and the rapid decay of electrochemical performance. Therefore, researchers have prepared some multi-dimensional materials with a topological structure. A double-carbon confinement strategy was presented by $\mathrm{Wu}$ et al. to prepare doublecarbon to confine $\mathrm{SnO}_{2}$ hollow nanospheres (denoted as G@C@SnO 2 ), as shown in Figure 1 [33]. The G@C@SnO showed a highly reversible performance in Li-ion batteries. The enhancement was ascribed to the following advantages: (i) a 3D structure based on graphene increased the conductivity, avoided the aggregation of nanoparticles, and provided an open framework for the transmission of electrons and ions; (ii) hollow $\mathrm{SnO}_{2}$ nanospheres shortened ion diffusion distance and buffered volume change; and (iii) a nitrogen-doped carbon shell can further accommodate volume change, ensuring structural integrity and improved conductivity.

\section{$\mathrm{SnO}_{2} @ \mathrm{C}$ Composites in Li-S Batteries}

Li-S battery is considered an excellent candidate for energystorage systems because of its high energy density. However, the sulfur cathode has the problem of low conductivity $\left(5 \times 10^{-30} \mathrm{~S}\right.$ 


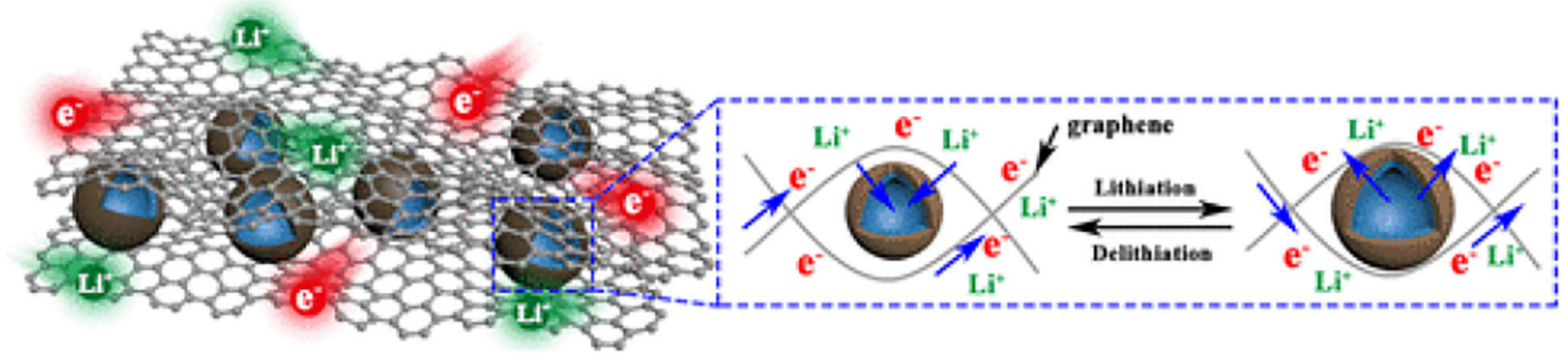

FIGURE 1 | Illustration of the reversible Li-ion storage in G@C@ $\mathrm{SnO}_{2}$. Reproduced from Wu et al. [33].

$\mathrm{cm}^{-1}$ ) and the huge volume-change during cycling, resulting in a rapid capacity decay $[7,37]$. In addition, polysulfide is easily soluble in electrolytes, leading to a shuttle effect [38]. Surface modification of sulfur cathodes and coating with conductive materials are common strategies to solve the problems [39]. Liu's group prepared a ternary composite of $\mathrm{S} / \mathrm{C} @ \mathrm{SnO}_{2}$, which could improve the conductivity of sulfur, adapt to the volume-change, and adsorb polysulfide [40]. Porous carbon could improve the conductivity, and the porous structure reserved space for the volume change of sulfur. In addition, the $\mathrm{SnO}_{2}$ shell improved the mechanical strength of the whole structure, displayed strong adsorption toward polysulfide, and further reduced the shuttle effect.

Moreover, $\mathrm{SnO}_{2}$ /carbon composites, as functional interlayer materials used in Li-S batteries, weaken the shuttle effect by chemical adsorption. In the meantime, carbon materials in $\mathrm{SnO}_{2} /$ carbon composite can improve the overall conductivity of the composite. Hu et al. prepared a $\mathrm{SnO}_{2} /$ reduced graphene oxide (rGO) composite as dual-function interlayer cathode material for Li-S batteries [41]. The close interaction between rGO and $\mathrm{SnO}_{2}$ nanoparticles not only reduced the resistance of the sulfur cathode but also averted the deformation of the electrode.

\section{$\mathrm{SnO}_{2} @ \mathrm{TMO}$ Composites in Secondary Batteries}

Typical transition metal oxides (TMOs), including $\mathrm{SnO}_{2}, \mathrm{TiO}_{2}$, $\mathrm{MoO}_{2}, \mathrm{Co}_{3} \mathrm{O}_{4}, \mathrm{~V}_{2} \mathrm{O}_{5}, \mathrm{NiO}, \mathrm{CuO}, \mathrm{ZnO}$, and $\mathrm{Fe}_{2} \mathrm{O}_{3}$, etc., commonly possess a high capacity compared to the graphite anode in Li-ion batteries [42, 43]. Researchers found that TMO composites are beneficial to the improvement of cycle stability, and they are attributed to the synergistic effect [4446]. Recently, many studies have been conducted in developing composites of $\mathrm{SnO}_{2}$ and TMOs. $\mathrm{SnO}_{2} @ \mathrm{TMO}$ composites are often used as anodes of Li-ion batteries, and they show good electrochemical performances. For example, $\mathrm{SnO}_{2}$ is n-typed semiconductor with a wide band gap $(3.6 \mathrm{eV})$, while $\alpha-\mathrm{Fe}_{2} \mathrm{O}_{3}$ is a p-type semiconductor with a narrow band gap $(2.2 \mathrm{eV})$. Electron transfer from the conduction band of $\mathrm{SnO}_{2}$ to the conduction band of $\alpha-\mathrm{Fe}_{2} \mathrm{O}_{3}$, crosses the heterojunction interface, and finally their Fermi levels reach an equilibrium. Figure 2 schematically shows the energy band of lithium storage of a $\mathrm{SnO}_{2} / \alpha-\mathrm{Fe}_{2} \mathrm{O}_{3}$ heterostructure. The synergistic effect of $\mathrm{SnO}_{2}$ and $\alpha-\mathrm{Fe}_{2} \mathrm{O}_{3}$ effectively improved the conductivity, and the diffusion rate of lithium ion thus improved the rate performance of the battery [47].

$\mathrm{SnO}_{2} @ \mathrm{TMO}$ has been used in many secondary batteries, such as Li-ion and Li-S batteries, exhibiting good performance. Liu et al. indicated that the low conductivity of pure sulfur and shuttle effect seriously hindered the commercial development of Li-S batteries [48]. The results showed the resistance of the $\mathrm{S} @ \mathrm{SnO}_{2} @ \mathrm{MnO}_{2}$ composite was $6.4 \times 10^{7} \Omega$, which was one order of magnitude lower than pure sulfur $\left(5.8 \times 10^{8} \Omega\right)$. According to the first-principal calculation, $\mathrm{SnO}_{2}$ and $\mathrm{MnO}_{2}$ had a compact band gap structure and a good density of states (DOS), which are helpful to the reduction of the electron transfer barrier. It was indicated that $\mathrm{SnO}_{2}$ and $\mathrm{MnO}_{2}$ improve the electrical conductivity and accelerate the electron transfer of $\mathrm{S} @ \mathrm{SnO}_{2} @ \mathrm{MnO}_{2}$ composite. The capacity of the Li-S battery with a $\mathrm{S} @ \mathrm{SnO}_{2} @ \mathrm{MnO}_{2}$ composite as the cathode was $1,323 \mathrm{mAh}$ $\mathrm{g}^{-1}$ at $0.1 \mathrm{C}$, and the low capacity decay rate was $0.03 \%$ after 500 cycles, indicating great confinement of the shuttle effect. In addition, the battery also showed good rate-performance.

\section{ELECTRON TRANSFER AND ION DIFFUSION OF DOPED-SnO 2 FOR ENERGY-STORAGE}

Doping technology is an economical, simple, and effective modification strategy that has been used broadly to improve the electronic properties of $\mathrm{SnO}_{2}$ in secondary batteries. Several materials have been chosen as dopants, including the group IIIA element ( $\mathrm{Al}, \mathrm{Ga}$, and $\mathrm{In}$ ), the group VA elements $\mathrm{Sb}$, and so on $[49,50]$. It has been reported that doping transition metals can not only increase the conductivity of $\mathrm{SnO}_{2}$ but also reduce the volume change in the process of circulation $[51,52]$. Lübke et al. reported two categories of transition metal dopants in $\mathrm{SnO}_{2}$ [53]. The first one are the elements without redox activity, including $\mathrm{Zr}$ [53], $\mathrm{Ti}$ [54], $\mathrm{Nb}$ [55], W [56], and $\mathrm{Pb}$ [57]. The doping of these elements will not change the capacity of $\mathrm{SnO}_{2}$, but it can significantly increase the cycling life and rate performance [53]. Dominic et al. indicated that the improvement of the performance of doped $\mathrm{SnO}_{2}$ depending on the increase 


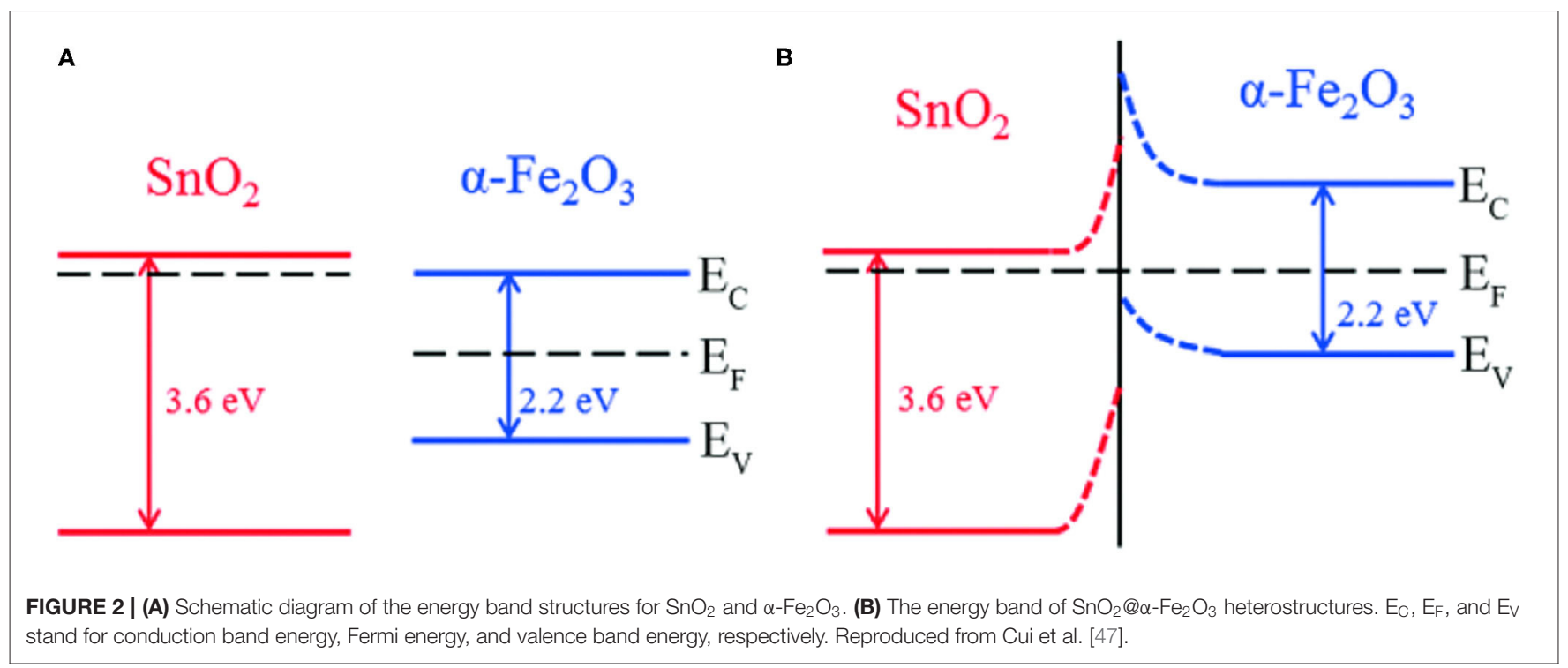

of the electrical conductivity caused by the additional charge percolation path. Belonging to the second group elements of $\mathrm{Cu}$ [53], Mn [58], Fe [59], Co [60], Ni [61], Zn [62], Mo [63], and Sb [64], which showed redox activity, can ensure participation in the conversion reaction, leading to the increase of theoretical capacity. Among them, Mo is an interesting dopant, as it increased the concentration of free electrons in $\mathrm{SnO}_{2}$. Chen et al. prepared ultrafine Mo-doped $\mathrm{SnO}_{2}$ in which Mo uniformly distributed and banded to a $\mathrm{SnO}_{2}$ lattice in the form of $\mathrm{Mo}^{6+}$ [63]. The initial capacity was as high as $2751.4 \mathrm{mAh} \mathrm{g}^{-1}$. Even at $0.5 \mathrm{~A} \mathrm{~g}^{-1}$, the initial capacity was $1121.8 \mathrm{mAh} \mathrm{g}^{-1}$, and the high capacity of $670.5 \mathrm{mAh} \mathrm{g}^{-1}$ can be maintained after 700 cycles. Moreover, Sb-doped $\mathrm{SnO}_{2}$ has also been studied widely. Wang et al. reported a $\mathrm{Sb}$-doped $\mathrm{SnO}_{2}$ hollow nanosphere that showed the capacity of $709 \mathrm{mAh} \mathrm{g}^{-1}$ at $0.1 \mathrm{~A} \mathrm{~g}^{-1}$ after 100 cycles [65].

In addition, doping and co-doping strategies by non-metallic elements are also reported, such as F [66-68], N [69], P [70], $\mathrm{S} / \mathrm{F}$ [71], and $\mathrm{Co} / \mathrm{F}$ [52]. It was reported that doping fluorine atoms in $\mathrm{SnO}_{2}$ could increase the electrical conductivity to about $5 \times 10^{3} \mathrm{~S} \mathrm{~cm}^{-1}$ [72]. In order to improve the Li-storage performance, Luo et al. chose active fluorine and sulfur atoms as dopants to prepare $\mathrm{S}$ and $\mathrm{F}$ co-doped $\mathrm{SnO}_{2} @$ graphene oxide binary composites [71]. On the one hand, fluorine atoms replaced $\mathrm{O}^{2-}$ in $\mathrm{SnO}_{2}$ to improve the electrical conductivity; on the other hand, S-doping enhanced Li-ion diffusion efficiency in the binary structure. The improvement of electronic conductivity can also be verified through the impedance spectra. Furthermore, the material can effectively reduce the volume expansion of electrode materials, thus reducing the capacity loss in the cycling process. It can be ascribed to the formation of the $\mathrm{SnS}_{\mathrm{x}}$ protective layer and $\mathrm{C}-\mathrm{F}$ bond on the surface of $\mathrm{SnO}_{2}$ and graphite oxide [71]. In addition, $\mathrm{Ma}$ et al. demonstrated the effect of doping ratio by comparing pure $\mathrm{SnO}_{2}$ and cobalt-doped $\mathrm{SnO}_{2}$ with the content of 5, 10, and 15\%, respectively [73]. They found the size of the synthesized particles decreased with the increase in dopant concentration. Electrochemical tests showed a doping ratio of $10 \%\left(\mathrm{Sn}_{0.9} \mathrm{Co}_{0.10} \mathrm{O}_{2}\right)$ possessed the best stability among the four samples.

\section{ELECTRON AND ION TRANSPORT IN Na- AND K-ION BATTERIES}

\section{$\mathrm{SnO}_{2}$ in $\mathrm{Na}$-Ion Batteries}

Because of the larger diameters of $\mathrm{Na}$ - and Li-ions than Li-ions $\left(\mathrm{K}^{+}>\mathrm{Na}^{+}>\mathrm{Li}^{+}, 1.38 \AA>1.02 \AA>0.76 \AA\right)$, the problems caused by volume change during the cycling are extremely critical, resulting in rapid capacity decay. In order to solve this problem, researchers have developed many strategies, such as nanostructures, making composites with carbon, etc. For example, Chen et al. used the synergistic-induced ultra-fine $\mathrm{SnO}_{2}$ /graphene nanocomposite as the cathode for a $\mathrm{K} / \mathrm{Na}$-ion battery, which showed a highly reversible capacity [36]. Xu et al. prepared a sandwich structure $\left(\mathrm{MWNTs@SnO} \mathrm{O}_{2} @ \mathrm{C}\right)$ in which MWNTs were coated with thick $\mathrm{SnO}_{2}, \mathrm{SnO}_{2}$, thin $\mathrm{SnO}_{2}$, and the carbon layer [74]. After removing the thick and thin $\mathrm{SnO}_{2}$, the larger internal space could alleviate the problems caused by $\mathrm{SnO}_{2}$ volume transformation, and the 1D MWNTs and carbon layer also improved the conductivity, which made the composite material have a better performance.

$\mathrm{Ma}$ et al. demonstrated the failure mechanism of the $\mathrm{SnO}_{2}$ electrode in Na- and K-ion batteries and indicated that OVs could manipulate the energy band structure and carrier migration, thus adjusting the intrinsic properties of oxide semiconductors [75]. In addition, Wang et al. used layer-by-layer-assembled porphyrin derivatives as an interface linker to uniformly attach $\mathrm{SnO}_{2}$ crystals to $\mathrm{N}$ and $\mathrm{S}$ co-doped graphene, achieving a high capacity and optimizing the electrochemical performance effectively [76].

\section{$\mathrm{SnO}_{2}$ in $\mathrm{K}$-Ion Batteries}

Owing to the significant advantages, such as fast interface diffusion rate, low price, and wide distribution, K-ion batteries have become a possible candidate to replace Li-ion batteries. 
Since 2015, research on K-ion batteries has become a hot spot. Some studies indicated that the use of $\mathrm{SnO}_{2}$ in $\mathrm{K}$-ion batteries can significantly alleviate the large volume change and the capacity decay.

Recently, Huang et al. reported the K-storage performance of $\mathrm{SnO}_{2} /$ carbon nanofibers [18]. Graphene was introduced through the electrospinning process, and the synergistic effect between $\mathrm{SnO}_{2}, \mathrm{rGO}$, and carbon was generated to improve the conductivity of the composites. Huang et al. doped $\mathrm{SnO}_{2} / \mathrm{rGO} / \mathrm{C}$ with phosphoric acid. The prepared composite showed an improved diffusion of $\mathrm{K}^{+}$ions after the modification by $\mathrm{H}_{3} \mathrm{PO}_{4}$ and an increased conductivity by $\mathrm{rGO}$, which further improves the electrochemical performance [77]. Suo et al. prepared $\mathrm{SnS}_{2} / \mathrm{SnO}_{2}$ heterostructures to enhance the K-storage performance through a facile two-step hydrothermal method to fix $\mathrm{SnS}_{2} / \mathrm{SnO}_{2}$ heterostructures onto stainless steel mesh $\left(\mathrm{SnS}_{2} / \mathrm{SnO}_{2} / \mathrm{SSM}\right)$. The $\mathrm{SnS}_{2} / \mathrm{SnO}_{2} / \mathrm{SSM}$ anode displayed an enhanced electrochemical performance [78]. Li et al. used amorphous carbon to coat $\mathrm{SnO}_{2}$ nanosheets, which exhibited good K-ion storage performance. The HCHS, as a stable carrier skeleton for $\mathrm{SnO}_{2}$ nanosheets, is good at providing high electrical conductivity. Amorphous carbon wrapping solved the problems of volume expansion and provided surface-induced capacitance [79].

\section{CONCLUSION}

In summary, the challenges for enhancing the electronic and ionic properties of $\mathrm{SnO}_{2}$ electrodes reported recently have been introduced. The conductivity and ion diffusion of $\mathrm{SnO}_{2}$ strongly depends on the structure and composition. Moreover, we indicated that the $\mathrm{SnO}_{2}$ exhibited great potential as the electrode

\section{REFERENCES}

1. Baidya S, Nandi C. Advances in greener energy technologies green energy and technology. Int $J$ Green Energy. (2020) 16:259-76. doi: 10.1007/978-981-15-4246-6_16

2. Periyasamy $\mathrm{M}$, Kar A. Modulating the properties of $\mathrm{SnO}_{2}$ nanocrystals: morphological effects on structural, photoluminescence, photocatalytic, electrochemical and gas sensing properties. J Mater Chem C. (2020) 8:460435. doi: 10.1039/C9TC06469A

3. Zoller F, Bohm D, Bein T, Fattakhova-Rohlfing, D. Tin oxide based nanomaterials and their application as anodes in lithium-ion batteries and beyond. ChemSusChem. (2019) 12:4140-59. doi: 10.1002/cssc.201901487

4. Fang R, Chen K, Yin L, Sun Z, Li F, Cheng HM. The regulating role of carbon nanotubes and graphene in lithium-ion and lithiumsulfur batteries. Adv Mater. (2019) 31:e1800863. doi: 10.1002/adma.2018 00863

5. Hosaka T, Kubota K, Hameed AS, Komaba S. Research development on K-ion batteries. Chem Rev. (2020) 120:6358-466. doi: 10.1021/acs.chemrev.9b00463

6. Kim T, Song WT, Son DY, Ono LK, Qi YB. Lithium-ion batteries: outlook on present, future, and hybridized technologies. J Mater Chem A. (2019) 7:2942-64. doi: 10.1039/C8TA10513H

7. Kumar R, Liu J, Hwang JY, Sun YK. Recent research trends in Li-S batteries. J Mater Chem A. (2018) 6:11582-605. doi: 10.1039/C8TA01483C

8. Liu Q, Hu Z, Chen M, Zou C, Jin H, Wang S, et al. Recent progress of layered transition metal oxide cathodes for sodium-ion batteries. Small. (2019) 15:e1805381. doi: 10.1002/smll.201805381 material with good volumetric and gravimetric capacities in many secondary batteries, including Li-ion, Li-S, Na-ion, and K-ion batteries, as displayed in Supplementary Tables 1-6. However, electrons and ions transport both require significant improvement. In order to address the issues and enable the application of $\mathrm{SnO}_{2}$-based secondary batteries, some approaches have been demonstrated. It is expected that possible investigations in the future will be focused on the optimization of the $\mathrm{SnO}_{2}$ structure, modifying this with some other functional dopants to seek ideal $\mathrm{SnO}_{2}$-based composites through both theoretical modeling and experimental preparation.

\section{AUTHOR CONTRIBUTIONS}

JL and $\mathrm{CH}$ supervised the mini-review. All authors prepared and approved the manuscript.

\section{FUNDING}

This work was supported by the Science and Technology Major Project of Anhui Province (18030901093), Key Research and Development Program of Wuhu (2019YF07), Natural Science Research Project for Universities in Anhui Province (KJ2018ZD034 and KJ2019A0502), and Foundation of Anhui Laboratory of Molecule-Based Materials (FZJ19014).

\section{SUPPLEMENTARY MATERIAL}

The Supplementary Material for this article can be found online at: https://www.frontiersin.org/articles/10.3389/fphy. 2021.669736/full\#supplementary-material
9. Li F, Liu Q, Hu J, Yang J, Ma J. Recent progresses on $\mathrm{SnO}_{2}$ anode materials for sodium storage. J Phys D Appl Phys. (2020) 53:353001. doi: 10.1088/1361-6463/ab8e79

10. Li HJ, Su QM, Kang J, Huang M, Feng M, Feng $\mathrm{H}$, et al. Porous $\mathrm{SnO}_{2}$ hollow microspheres as anodes for high-performance lithium ion battery. Mater Lett. (2018) 217:276-80. doi: 10.1016/j.matlet.2018.01.015

11. Yoshio IT, Kubota AM, Yukio M, Miyasaka T. Tin-based amorphous oxide: a high-capacity lithium-ion-storage material. Science. (1997) 276:1395-7. doi: $10.1126 /$ science.276.5317.1395

12. Park MS, Kang YM, Wang GX, Dou SX, Liu HK. The effect of morphological modification on the electrochemical properties of $\mathrm{SnO}_{2}$ nanomaterials. $\mathrm{Adv}$ Funct Mater. (2008) 18:455-61. doi: 10.1002/adfm.200700407

13. Xie J, Imanishi N, Hirano A, Takeda $\mathrm{Y}$, Yamamoto $\mathrm{O}$, Zhao XB, et al. Li-ion diffusion behavior in $\mathrm{Sn} \mathrm{SnO}$ and $\mathrm{SnO}_{2}$ thin films studied by galvanostatic intermittent titration technique. Solid State Ionics. (2010) 181:1611-5. doi: 10.1016/j.ssi.2010.09.006

14. Han TL, Wu Y, Ding YY, Zhong Y, Zhou P, Liu JY. Encapsulating tin nanoflowers into microcapsules for high-rate-performance secondary battery anodes through in situ polymerizing oil-in-water interface. Energy Technol. (2020) 8:1901404. doi: 10.1002/ente.201901404

15. Wu Y, Han TL, Zhou T, Qiao X, Chen X, Zhou P, et al. A novel silicon nanoparticles-infilled capsule prepared by an oil-in-water emulsion strategy for high-performance Li-ion battery anodes. Nanotechnology. (2020) 31:335403. doi: 10.1088/1361-6528/ab90b9

16. Liu JY, Cheng MY, Han TL, Lu QQ, Zhang HK, Zhou P, et al. A novel mechanically robust leaf-shaped tin dioxide Li-ion battery anode and its 
dynamic structural transformation and electron-transfer simulation. Energy Technol. (2020) 8:1901149. doi: 10.1002/ente.201901149

17. Kebede, Mesfin A. Tin oxide-based anodes for both lithium-ion and sodium-ion batteries. Curr Opin Electroche. (2020) 21:182-7. doi: $10.1016 /$ j.coelec.2020.02.003

18. Huang Z, Chen Z, Ding SS, Chen CM, Zhang M. Enhanced conductivity and properties of $\mathrm{SnO}_{2}$-graphene-carbon nanofibers for potassiumion batteries by graphene modification. Mater Lett. (2018) 219:19-22. doi: 10.1016/j.matlet.2018.02.053

19. Hernandez-Ramirez F, Tarancon A, Casals O, Pellicer E, Rodriguez J, Romano-Rodriguez A, et al. Electrical properties of individual tin oxide nanowires contacted to platinum electrodes. Phys Rev B. (2007) 76:085429. doi: 10.1103/PhysRevB.76.085429

20. Park MS, Wang GX, Kang YM, Wexler D, Dou SX, Liu HK. Preparation and electrochemical properties of $\mathrm{SnO}_{2}$ nanowires for application in lithium-ion batteries. Angew Chem Int edit. (2007) 46:750-753. doi: 10.1002/anie.200603309

21. Yin XM, Li CC, Zhang M, Hao QY, Liu S, Chen LB, et al. One-step synthesis of hierarchical $\mathrm{SnO}_{2}$ hollow nanostructures via self-assembly for high power lithium ion batteries. J Phys Chem C. (2010) 114:8084-8. doi: $10.1021 /$ jp $100224 \mathrm{x}$

22. Lee SH, Kim WB. Stripe- or square-patterned arrays of tin dioxide nanowires for use in lithium-ion battery electrodes. J Power Sources. (2016) 307:38-44. doi: 10.1016/j.jpowsour.2015.12.075

23. Wu S, Wang $\mathrm{M}$, Li C, Zhu Y, Wang $\mathrm{H}$. Single crystalline $\mathrm{SnO}_{2}$ nanowires obtained from heat-treated $\mathrm{SnO}_{2}$ and $\mathrm{C}$ mixture and their electrochemical properties. Mater Chem Phys. (2014) 147:184-90. doi: 10.1016/j.matchemphys.2014.04.028

24. Sennu P, Aravindan V, Lee YS. Marine algae inspired pre-treated $\mathrm{SnO}_{2}$ nanorods bundle as negative electrode for Li-ion capacitor and battery: an approach beyond intercalation. Chem Eng J. (2017) 324:26-34. doi: 10.1016/j.cej.2017.05.003

25. Teng XL, Zhang FL, Li Q, Wang X, Ye WN, Li HS, et al. Interfacial engineering of self-supported $\mathrm{SnO}_{2}$ nanorod arrays as anode for flexible lithium-ion batteries. J Electrochem Soc. (2020) 167:120515. doi: 10.1149/1945-7111/abac86

26. Man J, Liu K, Du YH, Sun JC. Self-assemble $\mathrm{SnO}_{2}$ porous nanotubes as high-performance anodes for lithium-ion batteries. Mater Chem Phys. (2020) 256:123669. doi: 10.1016/j.matchemphys.2020.123669

27. Mei J, Liao T, Sun Z. Two-dimensional metal oxide nanosheets for rechargeable batteries. J Energy Chem. (2018) 27:117-7, doi: $10.1016 /$ j.jechem.2017.10.012

28. Zhang $\mathrm{L}, \mathrm{Wu} \mathrm{HB}$, Lou X. Growth of $\mathrm{SnO}_{2}$ nanosheet arrays on various conductive substrates as integrated electrodes for lithium-ion batteries. Mater Horiz. (2014) 1:133-8. doi: 10.1039/C3MH00077J

29. Liu JY, Zhang M, Han TL, Si T, Zhang HG, Hu CQ. A general templateinduced sulfuration approach for preparing bifunctional hollow sulfides for high-performance Al- and Li-ion batteries. Energy Technol. (2020) 9:2000900. doi: 10.1002/ente.202000900

30. Zhang J, Ren H, Wang JY, Qi J, Yu Rb, Wang D, et al. Engineering of multishelled $\mathrm{SnO}_{2}$ hollow microspheres for highly stable lithium-ion batteries. $J$ Mater Chem A. (2016) 4:17673-7. doi: 10.1039/C6TA07717J

31. Long JW, Zhang HK, Ren JH, Li JJ, Zhu MF, Han TL, et al. A metal organic foam-derived multi-layered and porous copper sulfide scaffold as sulfur host with multiple shields for preventing shuttle effect in lithium-sulfur batteries. Electrochim Acta. (2020) 356:136853. doi: 10.1016/j.electacta.2020.136853

32. Cheng MY, Han TL, Zhang M, Zhang HK, Sun B, Zhu SG, et al. Hydrogel and sulfur co-coating on semispherical $\mathrm{TiO}_{2}$ as polysulfides-immobilized cathodes for high capacity and stable rate performance lithium-sulfur batteries. Appl Surf Sci. (2020) 513:145887. doi: 10.1016/j.apsusc.2020.145887

33. Wu Q, Shao Q, Li Q, Duan Q, Li Y, Wang HG. Dual carbon-confined $\mathrm{SnO}_{2}$ hollow nanospheres enabling high performance for the reversible storage of alkali metal ions. ACS Appl Mater Inter. (2018) 10:15642-51. doi: 10.1021/acsami.8b00605

34. Guo J, Li P, Chai LY, Su Y, Diao JX, Guo XH. Silica template-assisted synthesis of $\mathrm{SnO}_{2} @$ porous carbon composites as anode materials with excellent rate capability and cycling stability for lithium-ion batteries. RSC Adv. (2017) 7:30070-30079. doi: 10.1039/C7RA03594B
35. Gao CW, Jiang ZJ, Wang PX, Jensen LR, Zhang YF, Yue YZ. Optimized assembling of $\mathrm{MOF} / \mathrm{SnO}_{2} / \mathrm{Graphene}$ leads to superior anode for lithium ion batteries. Nano Energy. (2020) 74:104868. doi: 10.1016/j.nanoen.2020.104868

36. Chen WH, Song KM, Mi LW, Feng XM, Zhang JM, Cui SZ, et al. Synergistic effect induced ultrafine $\mathrm{SnO}_{2}$ /graphene nanocomposite as an advanced lithium/sodium-ion batteries anode. J Mater Chem A. (2017) 5:10027-38. doi: 10.1039/C7TA01634D

37. Balach J, Linnemann J, Jaumann T, Giebeler L. Metal-based nanostructured materials for advanced lithium-sulfur batteries. J Mater Chem A. (2018) 6:23127-68. doi: 10.1039/C8TA07220E

38. Zhang M, Zhu MF, Zhong Y, Han TL, Sun B, Zhu S, et al. A novel sulfur@void@hydrogel yolk-shell particle with a high sulfur content for volume-accommodable and poly-sulfide adsorptive lithium-sulfur battery cathodes. Nanotechnology. (2020) 31:455402. doi: 10.1088/1361-6528/abaa72

39. Chen L, Yu H, Li WX, Dirican M, Liu Y, Zhang XW. Interlayer design based on carbon materials for lithium-sulfur batteries: a review. J Mater Chem A. (2020) 8:10709-35. doi: 10.1039/D0TA03028G

40. Wu Y, Zhang W, Han TL, Shen Z, Cheng D, Zhang HK, et al. A novel ternary sulfur/carbon@tin dioxide composite with polysulfides-adsorptive shell and conductive core as high-performance lithium-sulfur battery cathodes. Appl Surf Sci. (2019) 489:462-9. doi: 10.1016/j.apsusc.2019.06.052

41. $\mathrm{Hu} \mathrm{N}, \mathrm{Lv} \mathrm{X}, \mathrm{Dai}$ Y, Fan L, Xiong D, Li X. $\mathrm{SnO}_{2} /$ reduced graphene oxide interlayer mitigating the shuttle effect of Li-S batteries. ACS Appl Mater Inter. (2018) 10:18665-74. doi: 10.1021/acsami.8b03255

42. Liu JY, Ding YY, Han TL, Long JW, Pei X, Luo Y, et al. An oriented laterallygrowing $\mathrm{NiCo}_{2} \mathrm{O}_{4}$ nanowire array on a $\mathrm{Fe}_{2} \mathrm{O}_{3}$ microdisc as a high-capacity and excellent rate-performance secondary battery anode. Chem Commun. (2020) 56:2618-21. doi: 10.1039/D0CC00553C

43. Han TL, Ding YY, Chen Y, Cheng D, Zhou P, Liu JY. A novel springstructured coaxial hierarchical $\mathrm{SiO}_{2} @ \mathrm{Co}_{3} \mathrm{O}_{4}$ nanowire as a lithium-ion battery anode and its in situ real-time lithiation. Nanotechnology. (2020) 31:035401. doi: 10.1088/1361-6528/ab4848

44. Choi J, Kim WS, Hong SH. Highly stable $\mathrm{SnO}_{2}-\mathrm{Fe}_{2} \mathrm{O}_{3}-\mathrm{C}$ hollow spheres for reversible lithium storage with extremely long cycle life. Nanoscale. (2018) 10:4370-6. doi: 10.1039/C7NR07208B

45. Zeng W, Zheng F, Li R, Zhan Y, Li Y, Liu J. Template synthesis of $\mathrm{SnO}_{2} /$ alpha$\mathrm{Fe}_{2} \mathrm{O}_{3}$ nanotube array for 3D lithium ion battery anode with large areal capacity. Nanoscale. (2012) 4:2760-5. doi: 10.1039/c2nr30089c

46. Zhu XS, Shi HM, Yin JW, Zhu HM, Zhou YM, Tang YW, et al. Facile preparation of $\mathrm{CuO} @ \mathrm{SnO}_{2}$ nanobelts as a high-capacity and long-life anode for lithium-ion batteries. RSC Adv. (2014) 4:34417-20. doi: $10.1039 / C 4 R A 04373 A$

47. Cui ZP, Sun M, Liu HQ, Li SJ, Zhang QY, Yang CP, et al. Doubleshell $\mathrm{SnO}_{2} @ \mathrm{Fe}_{2} \mathrm{O}_{3}$ hollow spheres as a high-performance anode material for lithium-ion batteries. Crystengcomm. (2020) 22:1197-208. doi: 10.1039/C9CE01621J

48. Zhou P, Han TL, Gu CP, Li JJ, Shen ZH, Zhang HG, et al. A novel wheelconfined composite as cathode in Li-S batteries with high capacity retention. J Alloy Compd. (2019) 776:504-10. doi: 10.1016/j.jallcom.2018.10.172

49. Skoromets V, Němec H, Kopeček J, KuŽel P, Peters K, FattakhovaRohlfing D, et al. Conductivity mechanisms in Sb-doped $\mathrm{SnO}_{2}$ nanoparticle assemblies: DC and terahertz regime. J Phys Chem C. (2015) 119:19485-95. doi: $10.1021 /$ acs.jpcc.5b05091

50. Zoller F, Peter K, Zehetmaier PM, Zeller P, Döblinger M, Bein T, et al Making ultrafast high-capacity anodes for lithium-ion batteries via antimony doping of nanosized tin oxide/graphene composites. Adv Funct Mater. (2018) 28:1706529. doi: 10.1002/adfm.201706529

51. Nithyadharseni P, Abhilash, KP, Petnikota S, Anilkumar MR, Jose R, Ozoemena, KI, et al. Synthesis and lithium storage properties of $\mathrm{Zn} \mathrm{Co}$ and $\mathrm{Mg}$ doped $\mathrm{SnO}_{2}$ nano materials. Electrochim Acta. (2017) 247:358-370. doi: 10.1016/j.electacta.2017.06.170

52. Pan D, Wan N, Ren Y, Zhang W, Lu X, Wang Y, et al. Enhanced structural and electrochemical stability of self-similar rice-shaped $\mathrm{SnO}_{2}$ nanoparticles. ACS Appl Mater Inter. (2017) 9:9747-55. doi: 10.1021/acsami.7b00232

53. Lübke M, Ning D, Armer Ceilidh F, Howard DB, Dan JL, Liu ZL, et al Evaluating the potential benefits of metal ion doping in $\mathrm{SnO}_{2}$ negative electrodes for lithium-ion batteries. Electrochim Acta. (2017) 242:400-7. doi: 10.1016/j.electacta.2017.05.029 
54. Ba CQ, Shi LY, Wang ZY, Chen GR, Wang S, Zhao Y, et al. Fabrication of Ti-doped $\mathrm{SnO}_{2} / \mathrm{rGO}$ composites as anode materials with high stability for lithium-ion batteries. Res Chem Intermediat. (2017) 43:5857-69. doi: 10.1007/s11164-017-2967-7

55. Zhang SL, Zhang JH, Cao GQ, Wang Q, Hu JH, Zhang P, et al. Strong interplay between dopant and $\mathrm{SnO}_{2}$ in amorphous transparent $(\mathrm{Sn}, \mathrm{Nb}) \mathrm{O}_{2}$ anode with high conductivity in electrochemical cycling. J Alloy Compd. (2018) 735:2401-9. doi: 10.1016/j.jallcom.2017.12.021

56. Wang S, Shi LY, Chen GR, Ba CQ, Wang ZY, Zhu JF, et al. In situ synthesis of tungsten-doped $\mathrm{SnO}_{2}$ and graphene nanocomposites for high-performance anode materials of lithium-ion batteries. ACS Appl Mater Inter. (2017) 9:17163-71. doi: 10.1021/acsami.7b03705

57. Zhao P, Yue WB, Yuan X, Bao HY. Exceptional lithium anodic performance of Pd-doped graphene-based $\mathrm{SnO}_{2}$ nanocomposite. Electrochim Acta. (2017) 225:322-9. doi: 10.1016/j.electacta.2016.12.124

58. Ma YJ, Ma Y, Guili G, Diemant T, Behm RJ, Geiger D, et al. Conversion/alloying lithium-ion anodes-enhancing the energy density by transition metal doping. Sustain Energ Fuels. (2018) 2:2601-8. doi: 10.1039/C8SE00424B

59. Yan Y, Du FH, Shen XP, Ji ZY, Sheng XX, Zhou H, et al. Large-scale facile synthesis of $\mathrm{Fe}$-doped $\mathrm{SnO}_{2}$ porous hierarchical nanostructures and their enhanced lithium storage properties. J Mater Chem A. (2014) 2:15875-82. doi: 10.1039/C4TA02077D

60. Liang BR, Wang JJ, Zhang SY, Liang XQ, Huang HF, Huang D, et al. Hybrid of Co-doped $\mathrm{SnO}_{2}$ and graphene sheets as anode material with enhanced lithium storage properties. Appl Surf Sci. (2020) 533:147447. doi: 10.1016/j.apsusc.2020.147447

61. Ye XM, Zhang WJ, Liu QJ, Wang SP, Yang YZ, Wei HY. One-step synthesis of $\mathrm{Ni}$-doped $\mathrm{SnO}_{2}$ nanospheres with enhanced lithium ion storage performance. New J Chem. (2015) 39:130-5. doi: 10.1039/C4NJ00989D

62. Jia TK, Chen J, Deng Z, Fu F, Zhao JW, Wang XF, et al. Facile synthesis of $\mathrm{Zn}$-doped $\mathrm{SnO}_{2}$ dendrite-built hierarchical cube-like architectures and their application in lithium storage. Mat Sci Eng B. (2014) 189:32-7. doi: 10.1016/j.mseb.2014.07.006

63. Chen YL, Ge DT, Zhang J, Chu RX, Zheng J, Wu CQ, et al. Ultrafine Mo-doped $\mathrm{SnO}_{2}$ nanostructure and derivative Mo-doped $\mathrm{Sn} / \mathrm{C}$ nanofibers for high-performance lithium-ion batteries. Nanoscale. (2018) 10:17378-87. doi: 10.1039/C8NR01195H

64. An GH, Lee DY, Lee YJ, Ahn HJ. Ultrafast lithium storage using antimony-doped tin oxide nanoparticles sandwiched between carbon nanofibers and a carbon skin. ACS Appl Mater Inter. (2016) 8:30264-70. doi: 10.1021 /acsami.6b10868

65. Wang S, Liu JX, Yu XH, Zhang YJ, Liu JM, Zhong ZR, et al. Antimony-doped $\mathrm{SnO}_{2}$ hollow nanospheres as negative materials for highperformance lithium-ion batteries. Int J Electrochem Soc. (2019) 14:9112-21. doi: $10.20964 / 2019.09 .78$

66. Cui DM, Zheng Z, Peng X, Li T, Sun TT, Yuan LJ. Fluorine-doped $\mathrm{SnO}_{2}$ nanoparticles anchored on reduced graphene oxide as a highperformance lithium ion battery anode. J Power Sources. (2017) 362:20-6. doi: 10.1016/j.jpowsour.2017.07.024

67. Sun JH, Xiao LH, Jiang SD, Li GX, Huang Y, Geng JX. Fluorine-doped $\mathrm{SnO}_{2} @$ Graphene porous composite for high capacity lithium-ion batteries. Chem Mater. (2015) 27:4594-603. doi: 10.1021/acs.chemmater.5b00885

68. Zhang YC, Wang RZ, Zheng Z, Li T, Tong ZQ, Ai CC. Fluorinedoped $\mathrm{SnO}_{2}$ /reduced graphene oxide-artificial graphite hybrids as lithium-ion battery anodes with stable capacity. Ionics. (2020) 26:2835-43. doi: 10.1007/s11581-020-03493-w

69. Wang LP, Leconte Y, Feng ZX, Wei C, Zhao Y, Ma Q, et al. Novel preparation of $\mathrm{N}$-doped $\mathrm{SnO}_{2}$ nanoparticles via laser-assisted pyrolysis: demonstration of exceptional lithium storage properties. Adv Mater. (2017) 29:1603286. doi: 10.1002/adma.201603286

70. Liu XW, Teng DH, Li T, Yu YH, Shao XH, Yang XP. Phosphorusdoped tin oxides/carbon nanofibers webs as lithium-ion battery anodes with enhanced reversible capacity. J Power Sources. (2014) 272:614-21. doi: 10.1016/j.jpowsour.2014.08.084

71. Luo Y, Yuan DD, Balogun MS, Yang H, Qiu WT, Liu JC, et al. Dual doping strategy enhanced the lithium storage properties of graphene oxide binary composites. J Mater Chem A. (2016) 4:13431-38. doi: 10.1039/C6TA05511G

72. Russo B, Cao GZ. Fabrication and characterization of fluorine-doped thin oxide thin films and nanorod arrays via spray pyrolysis. Appl Phys A Mater. (2007) 90:311-5. doi: 10.1007/s00339-007-4274-4

73. Ma YJ, Ma Y, Ulissi U, Ji YC, Streb C, Bresser D, et al. Influence of the doping ratio and the carbon coating content on the electrochemical performance of Co-doped $\mathrm{SnO}_{2}$ for lithium-ion anodes. Electrochim Acta. (2018) 277:100-9. doi: 10.1016/j.electacta.2018.04.209

74. Zhao Y, Wei C, Sun SN, Wang LP, Xu ZJ. Reserving interior void space for volume change accommodation: an example of cable-like MWNTs@SnO $\mathrm{O}_{2} @ \mathrm{C}$ composite for superior lithium and sodium storage. Adv Sci. (2015) 2:1500097. doi: 10.1002/advs.201500097

75. Ma DT, Li YL, Zhang PX, Lin ZQ. Oxygen vacancy engineering in tin(IV) oxide based anode materials toward advanced sodium-Ion batteries. ChemSusChem. (2018) 11:3693-703. doi: 10.1002/cssc.201801694

76. Wang HG, Wu Q, Wang YH, Wang X, Wu LL, Song SY, et al. Molecular engineering of monodisperse $\mathrm{SnO}_{2}$ nanocrystals anchored on doped graphene with high-performance lithium/sodium-storage properties in half/full cells. Adv Energy Mater. (2019) 9:1802993. doi: 10.1002/aenm.201802993

77. Huang Z, Chen Z, Ding SS, Chen CM, Zhang M. Enhanced electrochemical properties of $\mathrm{SnO}_{2}$-graphene-carbon nanofibers tuned by phosphoric acid for potassium storage. Nanotechnology. (2018) 29:19-22. doi: 10.1088/1361-6528/aace25

78. Suo GQ, Li D, Feng L, Hou XJ, Ye XH, Zhang L, et al. Construction of $\mathrm{SnS}_{2} / \mathrm{SnO}_{2}$ heterostructures with enhanced potassium storage performance. J Mater Sci Technol. (2020) 55:167-72. doi: 10.1016/j.jmst.2019. 05.074

79. Li D, Zhang JQ, Ahmed SM, Suo GQ, Wang W, Feng L, et al. Amorphous carbon coated $\mathrm{SnO}_{2}$ nanosheets on hard carbon hollow spheres to boost potassium storage with high surface capacitive contributions. J Colloid Interf Sci. (2020) 574:174-81. doi: 10.1016/j.jcis.2020.04.045

Conflict of Interest: The authors declare that the research was conducted in the absence of any commercial or financial relationships that could be construed as a potential conflict of interest.

Copyright (c) 2021 Han, Qi, Yang, Diao, Long, Zhu, Xu, Hu and Liu. This is an open-access article distributed under the terms of the Creative Commons Attribution License (CC BY). The use, distribution or reproduction in other forums is permitted, provided the original author(s) and the copyright owner(s) are credited and that the original publication in this journal is cited, in accordance with accepted academic practice. No use, distribution or reproduction is permitted which does not comply with these terms. 